\section{Accuracy of Irradiance and Power of Light-Curing Units Measured With Handheld or Laboratory Grade Radiometers}

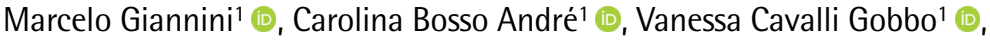 \\ Frederick Allen Rueggeberg² (i)
}

\author{
'Department of Restorative \\ Dentistry, Piracicaba Dental School, \\ UNICAMP - Universidade de \\ Campinas, Piracicaba, SP, Brazil \\ ${ }^{2}$ Department of Restorative Sciences, \\ Dental College of Georgia, Augusta \\ University, Augusta, GA, USA
}

Correspondence: Dra. Carolina Bosso André, Av. Limeira, 901, 13414-903 Piracicaba, SP, Brasil. Tel: +55-192106-5340. carolina.bosso@gmail.com

\begin{abstract}
This study measured and compared exitance irradiance and power of 4 commercial dental light-curing units (LCU) (Elipar S10, Elipar DeepCure-S, Corded VALO and Bluephase Style) using different types of radiometers. The devices used to analyze the LCU were classified as either handheld analog (Henry Schein, Spring, Demetron 100A, Demetron 100B and Demetron 200), handheld digital (Bluephase 1, Bluephase II, Coltolux, CureRite and Hilux), or laboratory instruments (Thermopile and Integrating Sphere). The laboratory instruments and the Bluephase II radiometer were also used to measure the LCU's power $(\mathrm{mW})$. The LCU's were activated for $20 \mathrm{~s}(\mathrm{n}=5)$. Data were analyzed using Kruskal-Wallis and Student-Newman-Keuls multiple comparison test $(\alpha=0.05)$. Among the LCU, the laboratory instruments presented different irradiance values, except for Corded VALO. The Coltolux and Hilux radiometers measured greater irradiance values compared to the laboratory instruments for the four LCUs tested. Within a given LCU, handheld analog units measured lower irradiance values, compared to handheld digital and laboratory instruments, except using the Spring radiometer for the Elipar S10 LCU. None of the handheld radiometers were able to measure similar irradiance values compared to laboratory instruments, except for Elipar S10 when comparing Bluephase 1 and Thermopile. Regarding power measurement, Bluephase II always presented the lowest values compared to the laboratory instruments. These findings suggest that the handheld radiometers utilized by practitioners (analog or digital) exhibit a wide range of irradiance values and may show lower outcomes compared to laboratory based instruments.
\end{abstract}

Key Words: polymerization, LED dental curing lights, power, irradiance.

\section{Introduction}

A major concern regarding dental light-curing units (LCUs) still remains whether or not sufficient radiant exposure $(\mathrm{J} / \mathrm{cm} 2)$ (time-based irradiance $(\mathrm{mW} / \mathrm{cm} 2)$ has been delivered to adequately polymerize resin-based composites (1). LCU irradiance is the radiant power $(\mathrm{mW})$ received over the target surface area and, unless a sufficient number of photons are received at the appropriate wavelengths, polymerization of the resin based composites can be inadequate (2). Inadequate photoactivation can negatively affect restoration properties: lowering the degree of conversion and the mechanical properties $(3,4)$, which can lead to fractures, secondary caries, restoration wear, and monomer leaching (5-7).

The extent of light-curing can be affected by differences in the spectral emission of LCUs $(1,8,9)$. The most common photoinitiator used in dental resin based composites is camphorquinone (10); however, alternative photoinitiators with different absorption peaks have been added in composites for bleached teeth or in order to improve mechanical properties, depth of cure, and color stability of the resulting restorations $(11,12)$. Therefore, some LCUs emit light consisting of two or more wavelengths ranges (multiple-peak lights) that will activate more than one photoinitiator $(13,14)$. However, such differences in emission spectra are not detected by handheld dental radiometers, because they only are responsive to the total number of photons detectable within a range predetermined by the manufacturer. In addition, the extent of angulation of the LCU tip with respect to the restoration surface and the tipto-target distance (or cavity depth) are also factors that can impair delivery of light energy and thus will negatively impact composite polymerization (15).

Many dental handheld radiometers are commercially available. A common feature of these units is that they usually contain silicon photodiodes that convert light into electric current, the value of which is then read by an analog or digital meter. The meter on these units has been "calibrated" by the manufacturer to reflect current readings known to be generated when specific levels of irradiance fall on the device's detector (16). A previous study identified differences in irradiance values between two handheld radiometers (17) and identified factors involved with the inaccuracy of these instruments. Degradation of the 
radiometer over time, variability in the original calibration, differences in light guide tip diameter, and type and spectral width of bandpass filters used were noted as some factors affecting accuracy of the dental radiometers tested (16).

A handheld radiometer is designed to measure exitance irradiance of LCUs and not the radiant exposure received by the restoration $(18,19)$ nor the LCU radiant power emitted. However, a new handheld dental radiometer was developed to measure both irradiance and radiant power of LCUs: Bluephase II (Ivoclar Vivadent, Schaan, Liechtenstein) (20). To date, little research exists comparing this new radiometer with the performance of other commercial products, or to that of laboratory based measurement instruments.

Thus, the purpose of this study was to compare irradiance values of a wide variety of contemporary

Table 1. Manufacturer and serial number of light curing unit (LCU) tested

\begin{tabular}{|c|c|c|c|}
\hline $\begin{array}{l}\text { LCU } \\
\text { product } \\
\text { name }\end{array}$ & $\begin{array}{c}\text { Optical } \\
\text { emission tip } \\
\text { diameter (mm) }\end{array}$ & Serial number & Manufacturer \\
\hline Elipar S10 & 9.08 & 939112009734 & \multirow{2}{*}{$\begin{array}{l}\text { 3M Oral Care, St. } \\
\text { Paul, MN, USA }\end{array}$} \\
\hline $\begin{array}{l}\text { Elipar } \\
\text { DeepCure-S }\end{array}$ & 8.78 & 93112000964 & \\
\hline $\begin{array}{l}\text { Corded } \\
\text { VALO }\end{array}$ & 9.06 & Prototype & $\begin{array}{l}\text { Ultradent Products, } \\
\text { South Jordan, UT, USA }\end{array}$ \\
\hline $\begin{array}{l}\text { Bluephase } \\
\text { Style }\end{array}$ & 8.85 & 1100000089 & $\begin{array}{l}\text { Ivoclar Vivadent, } \\
\text { Schaan, Liechtenstein }\end{array}$ \\
\hline
\end{tabular}

commercial LCUs among handheld dental radiometers and laboratory grade instruments. The null hypotheses tested are that (I) irradiance values would not be influenced by handheld radiometers and laboratory grade instruments used, (II) irradiance values would not be influenced by handheld analog and digital dental radiometers, and (III) power values measured by the new Bluephase II are similar to the values measured by laboratory grade instruments.

\section{Material and Methods}

Four LCUs were tested in this study: two single peak lights (Elipar S10 and Elipar DeepCure-S) and two multiplepeak lights (Corded VALO and Bluephase Style). The tip diameter of each light from which light emitted was measured using a digital caliper (Mitutoyo Co., Kanagawa, Japan) (Table 1).

\section{Handheld Radiometers}

To measure light output (irradiance $\left(\mathrm{mW} / \mathrm{cm}^{2}\right)$ or power $(\mathrm{mW}))$, different types of radiometers and power meters were used. The instruments were classified as handheld analog, handheld digital and laboratorial ones (Table 2). In addition, the only handheld meter capable of providing power measurements (Bluephase II) was also used to measure the LCU's power. Each LCU was positioned in a rigid stand with their tips placed parallel and in contact with the radiometer sensor area. A 20-s

Table 2. Manufacturer, serial number, and classification of the measurement's devices tested

\begin{tabular}{|c|c|c|c|c|}
\hline $\begin{array}{l}\text { Instrument } \\
\text { classification }\end{array}$ & Model Name & $\begin{array}{l}\text { Manuscript } \\
\text { reference name }\end{array}$ & Serial Number & Manufacturer \\
\hline \multirow{5}{*}{$\begin{array}{l}\text { Handheld } \\
\text { - Analog }\end{array}$} & Curing Light Meter 105 & Schein & 169 & Henry Schein Inc., Port Washington, NY, USA \\
\hline & Spring Light Meter & Spring & Not Available & Spring Health Products, Norristown, PA, USA \\
\hline & $\begin{array}{l}\text { Optilux Radiometer } \\
\text { Model 100, A) }\end{array}$ & Demetron $100 \mathrm{~A}$ & 135862 & Kerr Corporation, Danbury, CT, USA \\
\hline & $\begin{array}{l}\text { Optilux Radiometer } \\
\text { Model 100, B) }\end{array}$ & Demetron $100 \mathrm{~B}$ & 135859 & Kerr Corporation, Danbury, CT, USA \\
\hline & L.E.D. Radiometer & Demetron 200 & 793000339 & Kerr Corporation, Danbury, CT, USA \\
\hline \multirow{5}{*}{$\begin{array}{l}\text { Handheld } \\
\text { - Digital }\end{array}$} & Bluephase Meter & Bluephase 1 & 4762 & Ivoclar Vivadent, Schaan, Liechtenstein) \\
\hline & Bluephase Meter II & Bluephase II & 13000000339 & Ivoclar Vivadent, Schaan, Liechtenstein) \\
\hline & Coltolux Light Meter & Coltolux & 906122038 & Coltène/Whaledent, Mahwah, NJ, USA \\
\hline & CureRite & CureRite & 7390 & Dentsply Caulk, Milford, DE, USA \\
\hline & Hilux & Hilux & 9061785 & Benlioglu Dental, Ankara, Turkey) \\
\hline \multirow{2}{*}{$\begin{array}{l}\text { Laboratory } \\
\text { Instruments }\end{array}$} & $\begin{array}{l}\text { Fieldmate Laser Power } \\
\text { Meter PM10 air-cooled }\end{array}$ & Thermopile & 0307J08R & Coherent, Santa Clara, CA, USA \\
\hline & CTSM-LSM-60-SF & 6" Integrating Sphere & Not Available & Labsphere, Sutton, NH, USA \\
\hline
\end{tabular}


exposure was performed, in random order of radiometer and LCU, with the tip repositioned after each measurement $(n=5)$. Prior to testing, the handheld radiometers that were battery operated were supplied with fresh batteries.

\section{Laboratory Instruments}

Two laboratory power meters were used to evaluate the irradiance and the power of the LCUs and those values were compared with measurements obtained using the handheld radiometers. One instrument consisted of a radiospectrometer calibrated to a NIST-traceable light source. This system consisted of a 6" integrating sphere LabSphere, Sutton, $\mathrm{NH}_{\text {, }}$ USA) that was connected to a small spectrometer (USB 2000, Ocean Optics, Dunedin, FL, USA), which was connected to a personal computer. Spectral power measurements were obtained using software (SpectraSuite, Ocean Optics), where the integrated area between 350 and $550 \mathrm{~nm}$ was summed to provide a total power emission. To convert that value into irradiance units, the measured power value was divided by the emitting tip area from which light was generated. The other measurement device was a thermopile sensor (PowerMax PM-10, Coherent Inc, Santa Clara, CA, USA) that has also been calibrated to a NIST-tracable light source. The LCUs were fixed on a rigid stand and the light tip was placed slightly into the entrance aperture of the integrating sphere, or was held close (but not in contact with the tip sensor) on the thermopile. A 20-s exposure was performed in random order of laboratory instrument and LCU, allowing the tip to be repositioned each time $(n=5)$, as described for handheld devices.

Measured irradiance and power values were submitted to a normality test and were analyzed using the Kruskal-Wallis and Student-NewmanKeuls multiple comparison test at a pre-set alpha of 0.05 .

\section{Results}

Within each LCU, a one-way ANOVA failed to pass the Shapiro-Wilk normality test $(p<0.05)$, so nonparametric analyses were used to compare irradiance or power values among types of light measurement systems within each LCU.

Figures 1 to 4 present the median irradiance (in $\mathrm{mW} / \mathrm{cm}^{2}$ ) and Figure 5 depicts the median power (in $\mathrm{mW}$ ) for the handheld radiometers and laboratory instruments, according to each LCU tested. Overall, similar trends of irradiance and power measured with handheld radiometers and laboratory instruments were noted for all LCUs (single- or multiple-peaks).

Lower irradiance values were observed using the analog-metered handheld radiometers than those obtained with digital models, except for Elipar S10 when measured with Bluephase II compared to Spring (Fig. 1). In general, all irradiance values of LCUs obtained using

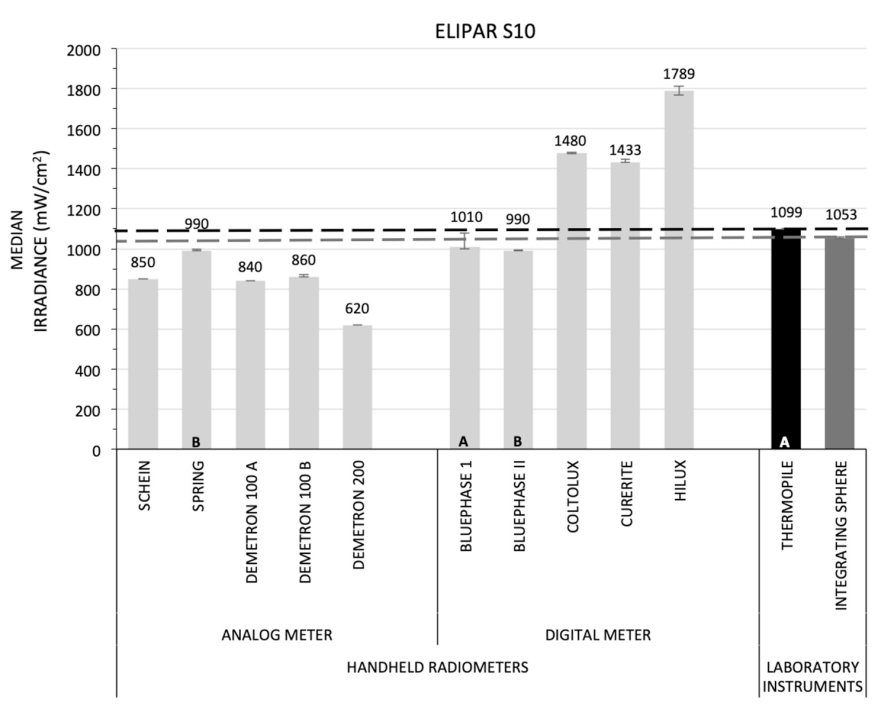

Figure 1. Median irradiance values of handheld radiometers and laboratory instruments for the Elipar S10 light. Vertical bars represent 25\% and 75\% quartile values. Similar upper case letters indicate no significant difference between measured irradiance values.

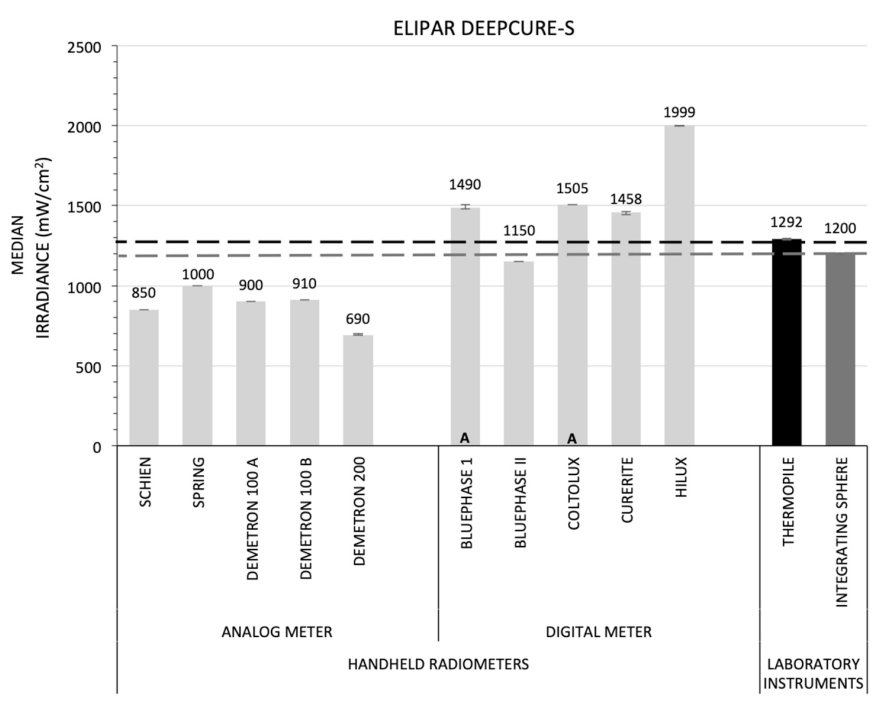

Figure 2. Median irradiance values of handheld radiometers and laboratory instruments for the Elipar DeepCure-S light. Vertical bars represent 25\% and $75 \%$ quartile values. Similar upper case letters indicate no significant difference between measured irradiance values. 
handheld radiometers were statistically different. Except for Corded Valo, irradiance values obtained using the laboratory instrumentation did not differ statistically (Fig. 3). Coltolux, CureRite and Hilux units demonstrated greater irradiance values compared to the others digital and analog radiometers and laboratory instruments, except for Bluephase Style comparing CureRite with Integrating Sphere (Fig. 4).

For all LCUs, the power measurement using Bluephase II handheld radiometer (a unit uniquely capable of that feature) was significantly lower than those obtained with both laboratory grade instrument. The power measured with thermopile and Integrating Sphere did not differ between them only for Corded Valo.

\section{Discussion}

Considering that each type of meter (analog or digital handheld radiometers or laboratory instruments) showed different irradiance results, and that the Bluephase II device indicated lower power values compared to the laboratory grade instruments, all three null hypotheses were rejected.

$\vec{s}$ Although a statistical difference was found, the Bluephase 1 and Bluephase II devices measured irradiance values nearest those found for the laboratory instruments, for all lights tested. Overall, the Bluephase II meter measured approximately $10 \%$ lower irradiance values compared to the laboratory instruments, except for Bluephase Style LCU, which ranged near 14\%. The Bluephase 1 device demonstrated irradiance values for Elipar DeepCure-S compared to the laboratory instruments by approximately $15 \%$. In general, the Bluephase II had an accuracy of $10 \%$ compared to a laboratorygrade meter, the same claimed by the manufacturer (20).

As demonstrated in the results, dental radiometers are not considered a substitute for use of laboratory grade measuring instruments, for either irradiance or power. In addition, there was a great variation among handheld radiometer brands, with those using an analog style generally providing lower irradiance values than the digital ones. This variation may be explained by differences in size and type of the sensor of these handheld radiometers (20). Usually these devices contain a small silicon photodiode detector that converts the LCU photons into electrical current, and than into units of irradiance (21). Difference in sensor size of the handheld radiometers can influence the irradiance results because the irradiance is the quotient of the power and the area of the LCU tip (20). A small detector and a narrow entrance aperture of the dental radiometers avoid it to measure all of the light from the LCU (21). Also, the light diffusor of the dental radiometers may not be able to prevent the measurement of the hot spots (20). Thus, handheld dental curing radiometers are not recommended to accurately report irradiance

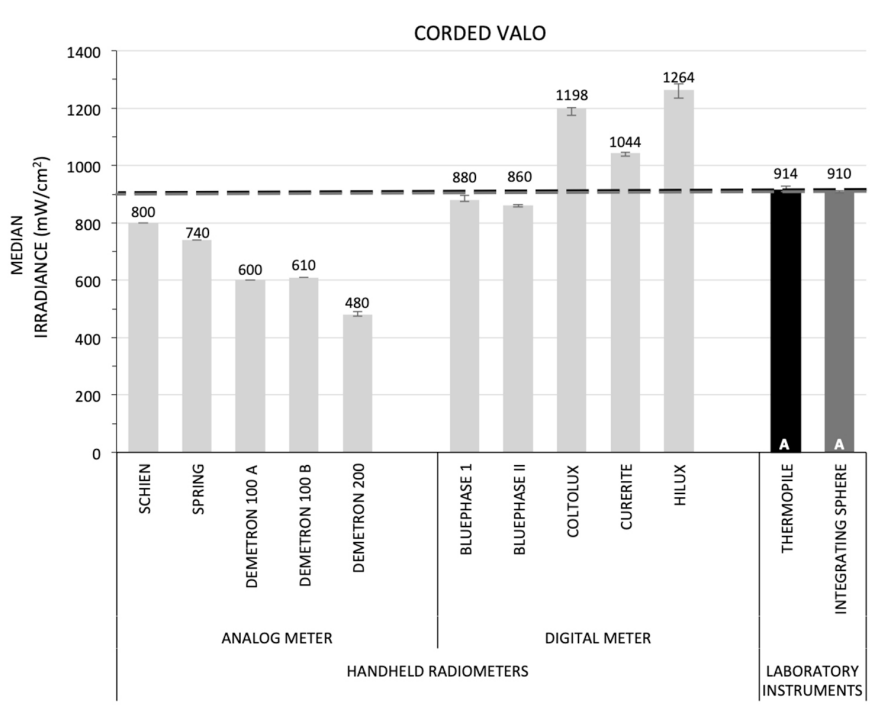

Figure 3. Median irradiance values of handheld radiometers and laboratory instruments for corded VALO light. Vertical bars represent 25\% and 75\% quartile values. Similar upper case letters indicate no significant difference between measured irradiance values.

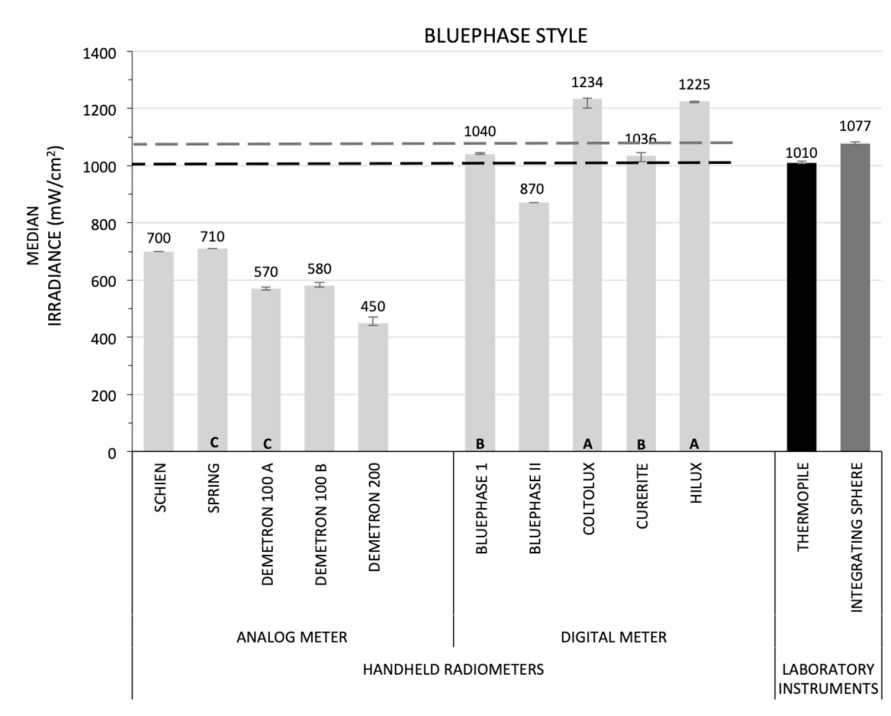

Figure 4. Median irradiance values of handheld radiometers and laboratory instruments for Bluephase Style light. Vertical bars represent 25\% and 75\% quartile values. Similar upper case letters indicate no significant difference between measured irradiance values. 
and should not be used in research studies. In addition, clinicians should not compare different LCUs using dental radiometers because of the uncertainty of the results (16). Development of an accurate handheld dental radiometers that could measure any type of LCU and could be used by practitioners is still required (22).

The main purpose of these handheld radiometers is to provide an easy method of evaluating the performance of the light emitted by an LCU so that clinicians can tell if light output has significantly changed, and if so, then appropriate means can be taken to compensate for such loss, or the unit might need repair. By monitoring exitance irradiance levels over time, the clinician may determine of the light chip is failing, if the light guide or tip lens is contaminated or chipped, or if the batteries of the LCU are not charging correctly and need replacement. Because evaluation of light output using the human eye is not appropriate or advised for these purposes, an instrument capable of providing accurate results is needed.

Despite the variation in irradiance values found among the dental handheld radiometers tested, these meters can still be used as accurate monitors of the output light of a given LCU over time $(10,16,17)$. If irradiance values decrease from when the LCU was new, for instance 10\%, the practitioners needs to determine the source of the problem. Possible causes of output decrease can include adherent debris on the tip end or chips in the glass of the light-emitting surfaces $(23,24)$. An irradiance decrease can be related to either problems in LED chip, issues related to the LCU guide, or even the lens at the end of a pencilstyle unit (25).

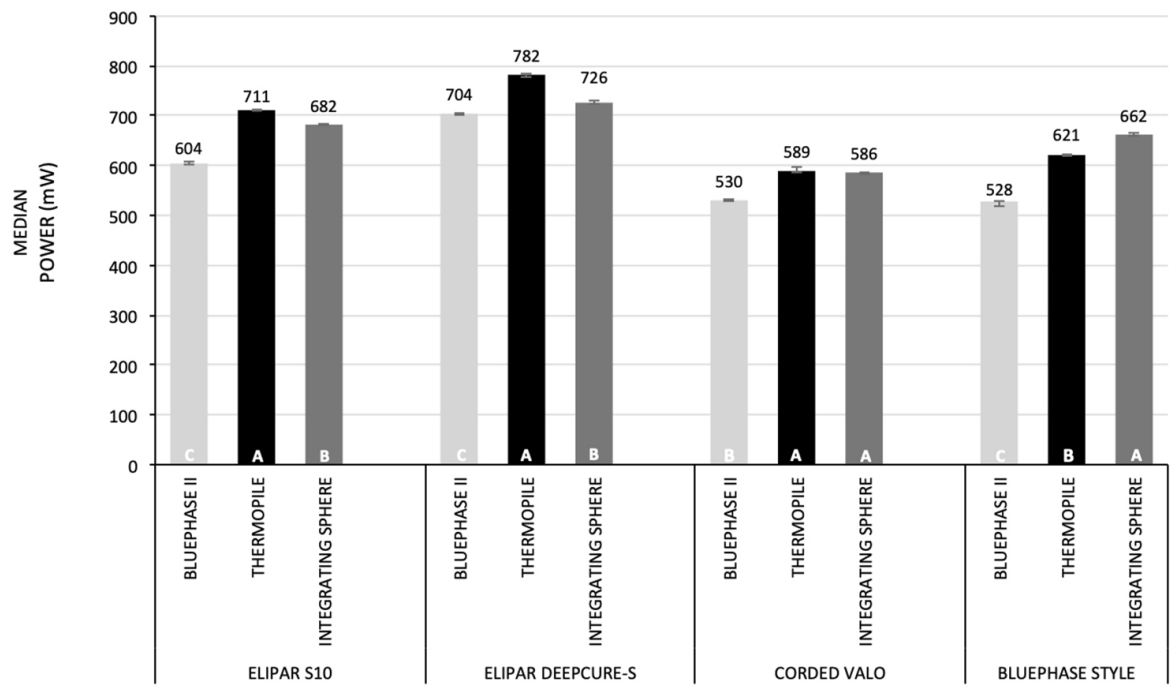

Figure 5. Median power values of Bluephase II and laboratory instruments for all LCUs tested. Vertical bars represent $25 \%$ and $75 \%$ quartile values. Similar upper case letters indicate no significant difference between measured power values.
One of the most common causes of decreased LCU output is related to debris contamination at the emitting tip end (21). That debris consists of bonding agents or other restorative materials that have come into contact with the tip as those materials are photocured. As a result, the polymerized materials may become tenaciously adherent to the glass tip surface. Simple whipping with a gauze soaked in ethanol or some other solvent will not remove this material. However, very careful scraping away of the material using a sharp razor blade works well, and will not damage the glass surface underneath. Personnel need to use great caution when using this method and are warned of the great possibility of inadvertently cutting fingers and hands. A safer and effective method is to merely immerse the contaminated tip end into a bolus of uncured composite slightly larger than the tip diameter. By activating the LCU while the composite is still in contact with the end, the freshly polymerizing composite will adhere to the already cured composite clinging onto the glass surface. Following the light exposure, if an edge of the freshly cured composite is pulled, the entire mass will pop off the contaminated tip end, leaving a much cleaner surface. This process might have to be repeated a number of times to completely remove all adherent material. Of course, use of the clear barrier films over the tip ends will also prevent tip contamination (26).

The monitoring irradiance a given LCU over time, attention needs to be given to use a standardized methodology to avoid great variations in readings (25). The following guidelines should be followed: (I) always use the same light guide to measure irradiance (different tips diameters provide different irradiance values) (20), (II) orient the light guide with the body of the LCU in exactly the same manner each time, (III) orient the attached light guide in exactly the same position with respect to the radiometer sensor every time $(20,21)$, and (IV) ensure that the light-emitting tip end is totally flat against the detector port of the radiometer, and not angled $(15,26)$.

Rotations of the light guide with respect to the curing unit, or the rotation of the tip with the respect of the radiometer may result in great variation in readings. When testing a pencil-style LCU with the emitting diodes 
at the tip end, the long axis of the unit should also be placed at the same position each time a measurement is made.

Resin composite materials require different radiant exposure levels to optimally polymerize (27) and the instructions for use of composites usually specify the recommended exposure duration based upon the general irradiance measurement of the light (28). Thus, in one way, a valid irradiance value is needed in order to provide adequate radiant power, and consequently providing optimal composite curing and long-term clinical performance of a restoration. However, as showed by the test results, there is a tremendous variation of readings among handheld radiometers, even when different types of lights are being tested. As a more appropriate method of the efficacy of light exposure of a given LCU with the composite material used in a clinician's office, the clinician should perform an in-office depth of cure test. In this manner, a physical specimen is generated using the specific instrument and material in the dental office, and variation of exposure time and tip distance can be evaluated to provide a total picture of how the operator should adjust for variations in clinically relevant parameters in order to obtain optimal performance from their photo-cured restorations. (29).

When in doubt, practitioners should use longer exposure times, always cooling the tooth to prevent over-heating the pulp $(10,30)$. One suggested method for cooling the tooth can easily be performed by directing an air stream over the crown of the tooth (or pulling air over the crown using a high speed vacuum tip), during the light exposure $(24,25)$. In addition, the photoinitiator absorption spectrum of the restorative material should match the spectral output of the light, in order to achieve optimal polymerization $(1,31)$.

The Bluephase II handheld meter is currently the only device that provides data of both irradiance and power of an LCU. However, it presents the same inaccuracy regarding other meters because it does not consider the exact internal (optical) tip diameter of LCU. For using the thermophile and integrating sphere laboratory instruments, the internal tip area of each light is considered, which ensures more precise light measurements (32). In addition, both of those instruments capture all radiant power emitted from the light, while hand-held radiometers only analyze a smaller inner core of the tip-end radiation. The Bluephase II uses a scale (6 to $12 \mathrm{~mm}$ ) molded on the back of the device to measure the tip diameter. However, this scale considers only the external tip diameter not the optical one. Also, for some LCUs is not possible to fit the tip properly on this scale. Thus, although this handheld meter has this new function to measure the power, the value given by this meter might not be reliable, because the results of the current study were always significantly different from those of laboratory grade instruments, regardless the LCU.
The tested handheld radiometers, both analog and digital, exhibit a wide range of irradiance values and are not recommended as a substitute for use of laboratory grade instruments for irradiance. Also, irradiance and power results obtained with Bluephase II did not match with laboratory grade instruments.

\section{Resumo}

Esse estudo mensurou e comparou a irradiância e a energia de quatro fotopolimerizadores comerciais (Elipar S10, Elipar DeepCure-S, Corded VALO e Bluephase Style) utilizando diferentes tipos de radiômetros. Os dispositivos utilizados para analisar os fotopolimerizadores foram classificados em portáteis analógicos (Henry Schein, Spring, Demetron 100A, Demetron 100B e Demetron 200), portáteis digitais (Bluephase 1, Bluephase II, Coltolux, CureRite e Hilux), ou instrumentos laboratoriais (Thermopile e Integrating Sphere). Os instrumentos laboratoriais e o radiômetro Bluephase II também foram utilizados para medir a energia dos fotopolimerizadores $(\mathrm{mW})$. Os fotopolimerizadores foram ativados por $20 \mathrm{~s}(\mathrm{n}=5)$. Os dados foram analisados utilizando Kruskal-Wallis e teste de Student-Newman-Keuls $(\alpha=0,05)$. Dentre os fotopolimerizadores, os instrumentos laboratoriais apresentaram diferentes valores de irradiância, exceto para o Corded VALO. 0 Coltolux e o Hilux mensuraram uma irradiância maior comparado aos instrumentos de laboratório para os quatro fotopolimerizadores testados. Para o mesmo fotopolimerizador, os radiômetros analógicos portáteis mensuraram menores valores de irradiância quando comparados aos digitais portáteis ou aos instrumentos laboratoriais, exceto quando utilizado o Spring para o Elipar S10. Nenhuma diferença foi observada entre os instrumentos laboratoriais na irradiância do Corded VALO. Para a medição da energia, nenhuma diferença foi observada usando Thermopile e a Integrating Sphere para o Corded VALO. Para os outros fotopolimerizadores, cada instrumento indicou uma energia diferente. Esses achados sugerem que radiômetros portáteis utilizados pelos cirurgiões-dentistas (analógico ou digital) exibem uma ampla gama de valores de irradiância e podem mostrar medidas inferiores comparados aos instrumentos de laboratório.

\section{Acknowledgements}

This study was supported by Brazilian Financial Agencies: FAEPEXUNICAMP (2054/16) and CNPq (307217-2014-0).

\section{References}

1. Leprince JG, Palin WM, Hadis MA, Devaux J, Leloup G. Progress in dimethacrylate-based dental composite technology and curing efficiency. Dent Mater 2013;29:139-156.

2. Price RB, Felix CA, Andreou P. Effects of resin composite composition and irradiation distance on the performance of curing lights. Biomaterials 2004;25:4465-4477.

3. Ferracane JL. Resin-based composite performance: are there some things we can't predict? Dent Mater 2013;29:51-58.

4. Dewaele M, Asmussen E, Peutzfeldt A, Munksgaard EC, Benetti AR, Finné $G$, et al. Influence of curing protocol on selected properties of light-curing polymers: degree of conversion, volume contraction, elastic modulus, and glass transition temperature. Dent Mater 2009;25:1576-1584.

5. AIShaafi MM, Harlow JE, Price HL, Rueggeberg FA, Labrie D, AIQahtani $M 0$, et al. Emission characteristics and effect of battery drain in "budget" curing lights. Oper Dent 2016;41:397-408.

6. Shortall A, El-Mahy W, Stewardson D, Addison 0, Palin W. Initial fracture resistance and curing temperature rise of ten contemporary resin-based composites with increasing radiant exposure. J Dent 2013;41:455-463.

7. Sunitha C, Kailasam V, Padmanabhan $S$, Chitharanjan AB. Bisphenol $A$ release from an orthodontic adhesive and its correlation with the 
degree of conversion on varying light-curing tip distances. Am J Orthod Dentofacial Orthop 2011;140:239-44.

8. Price RB, Ferracane JL, Shortall AC. Light-curing units: a review of what we need to know. J Dent Res 2015;94:1179-1186.

9. Haenel T, Hausnerova B, Steinhaus J, Price RB, Sullivan B, Moeginger B. Effect of the irradiance distribution from light curing units on the local micro-hardness of the surface of dental resins. Dent Mater 2015;31:93104.

10. Rueggeberg FA. State-of-the-art: dental photocuring--a review. Dent Mater 2011;27:39-52.

11. Leprince J, Devaux J, Mullier T, Vreven J, Leloup G. Pulpal-temperature rise and polymerization efficiency of LED curing lights. Oper Dent 2010;35:220-230.

12. Kaisarly D, Gezawi ME. Polymerization shrinkage assessment of dental resin composites: a literature review. Odontology 2016;10:257-270.

13. Harlow JE, Sullivan B, Shortall AC, Labrie D, Price RB. Characterizing the output settings of dental curing lights. J Dent 2016;44:20-26.

14. Jandt KD, Mills RW. A brief history of LED photopolymerization. Dent Mater 2013;29:605-617.

15. Konerding KL, Heyder M, Kranz S, Guellmar A, Voelpel A, Watts DC, et al. Study of energy transfer by different light curing units into a class III restoration as a function of tilt angle and distance, using a MARC Patient Simulator (PS). Dent Mater 2016;32:676-686.

16. Price RB, Labrie D, Kazmi S, Fahey J, Felix CM. Intra- and inter-brand accuracy of four dental radiometers. Clin Oral Investig 2012;16:707717.

17. Rueggeberg FA. Precision of hand-held dental radiometers. Quintessence Int 1993;24:391-396.

18. Price RB, Felix CM, Whalen JM. Factors affecting the energy delivered to simulated class I and class $v$ preparations. J Can Dent Assoc 2010;76:a94.

19. André CB, NimaG, Sebold M, Giannini M, Price RB. Stability of the light output, tip oral cavity accessibility in posterior region and emission spectrum of light-curing units. Oper Dent 2018;43:398-407.

20. Shimokawa CA, Harlow JE, Turbino ML, Price RB. Ability of four dental radiometers to measure the light output from nine curing lights. J Dent 2016;54:48-55.

21. Price RBT. Light Curing in Dentistry. Dent Clin North Am 2017;61:751778.
22. Kameyama A, Haruyama A, Asami M, Takahashi T. Effect of emitted wavelength and light guide type on irradiance discrepancies in hand-held dental curing radiometers. ScientificWorldJournal 2013;2013:647941.

23. Poulos JG, Styner DL. Curing lights: changes in intensity output with use over time. Gen Dent 1997;45:70-73.

24. Roulet JF, Price R. Light curing - guidelines for practitioners - a consensus statement from the 2014 symposium on light curing in dentistry held at Dalhousie University, Halifax, Canada. J Adhes Dent 2014;16:303-304.

25. Rueggeberg FA, Giannini $M$, Arrais CAG, Price RBT. Light curing in dentistry and clinical implications: a literature review. Braz Oral Res 2017;31.

26. Price RB, Shortall AC, Palin WM. Contemporary issues in light curing. Oper Dent 2014;39:4-14.

27. Sword RJ, Do UN, Chang JH, Rueggeberg FA. Effect of curing light barriers and light types on radiant exposure and composite conversion. J Esthet Restor Dent 2016;28:29-42.

28. Rueggeberg FA, Cole MA, Looney SW, Vickers A, Swift EJ. Comparison of manufacturer recommended exposure durations with those determined using biaxial flexure strength and scraped composite thickness among a variety of light-uring units. J Esthet Restor Dent 2009;21:43-61.

29. Rueggeberg FA, Swift EJ, Jr. Exposure times for contemporary composites. J Esthet Restor Dent 2013;25:82-84.

30. Hannig $M$, Bott $B$. In-vitro pulp chamber temperature rise during composite resin polymerization with various light-curing sources. Dent Mater 1999;15:275-281.

31. Shortall AC, Felix CJ, Watts DC. Robust spectrometer-based methods for characterizing radiant exitance of dental LED light curing units. Dent Mater 2015;31:339-350.

32. Price $R B$, Labrie $D$, Rueggeberg $F A$, Felix $C M$. Irradiance differences in the violet $(405 \mathrm{~nm})$ and blue $(460 \mathrm{~nm})$ spectral ranges among dental light-curing units. J Esthet Restor Dent 2010;22:363-377.

Received November 30, 2018 Accepted January 24, 2019 